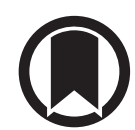

CrossMark

\title{
Ethical obligations for supporting healthcare workers during the COVID-19 pandemic
}

\author{
To the Editor:
}

During the coronavirus disease 2019 (COVID-19) pandemic, some healthcare facilities have, at times, reached the limits of their capacity to handle the surge in patient volume. Hospital beds and other medical resources became scarce as a consequence. Healthcare workers (HCWs), both clinical and non-clinical, were required to increase their workload, under extremely stressful circumstances.

HCWs are routinely exposed to numerous stressors, which results in high rates of burnout, post-traumatic stress disorder and suicide, especially among those working in high intensity environments [1]. This has been especially true during the COVID-19 pandemic [2]. Physically stressful working conditions and witnessing the suffering and death of large numbers of patients take a toll. Further, when resources cannot fully meet demand, HCWs may experience moral distress due to rationing decisions [3]. In addition, being confronted with a highly contagious pathogen such as severe acute respiratory syndrome coronavirus 2 (SARS-CoV-2), there is also the fear of becoming infected oneself or spreading the infection to one's family (table 1) [4]. This stress may contribute to physical exhaustion and feelings of fear and anxiety, sleep disorders and insomnia, or even burnout and depression [2]. All of this is compounded in a situation like a pandemic where the effects are felt beyond the work environment, giving HCWs the sense that there is no way to escape the pressures outside the hospital. Anxiety is further heightened by the uncertainty about when the pandemic will end or how bad it will get. With all of this psychological trauma, some HCWs will need extra time away from the hospital; some may never return to their jobs. As a consequence, healthcare facilities and systems could lose HCWs precisely at a time when they are needed most, further aggravating the situation of scarcity created by the increased demand. Therefore, it is crucial to keep working conditions as safe as possible in times of crisis. As patient surge reaches critical limits, tasks not absolutely necessary for patient care should be reduced as much as possible, while preserving safety.

Ongoing support for HCWs is critical at all levels, for instance, from family, friends and colleagues, as well as healthcare institutions, professional organisations, governments and society at large. The support must be aimed at protecting and maintaining the mental and physical wellbeing of HCWs and early identification of when they are at risk. For the individual, this support may come in many forms, such as meditation, exercise, creative arts therapy, and religious or spiritual activities. Furthermore, interprofessional teams caring for patients, especially in intensive care units, need to be assisted in fostering community [5]. Psychological support for those in need may include a trauma psychologist in those regions deeply affected by the pandemic. This support could also help counteract "social contagion", an aggravation of symptoms among peers [6].

The issue of supporting HCWs, however, is not only a question of physical and mental health; there are moral questions of responsibility, solidarity and justice at stake. HCWs not only have a professional and legal obligation to provide care for patients, but also a moral obligation [7]. This moral obligation is reflected by the acceptance of professional codes like the Hippocratic oath and the codes of various medical and allied health associations. However, the extent to which this obligation is appropriate in a situation where the acceptance of it would entail a significant threat to the HCWs own health and well-being is debatable. Neither heroism nor self-sacrifice can be demanded based on a perceived moral obligation [7].

@ERSpublications

Based on considerations of justice, healthcare workers must be able to rely on support and protection from the societies in which they work. Prioritisation of healthcare workers for vaccines may be a way to maintain a functioning healthcare system. https://bit.ly/3pouzQu

Cite this article as: Supady A, Curtis JR, Brown CE, et al. Ethical obligations for supporting healthcare workers during the COVID-19 pandemic. Eur Respir J 2021; 57: 2100124 [https://doi.org/10.1183/ 13993003.00124-2021]. 
TABLE 1 Stressors for healthcare workers (HCWs) during the coronavirus disease 2019 (COVID-19) pandemic

Stressor

Physical stress

Extra hours

Fear of becoming infected or transmitting infections to non-COVID-19 patients, family or friends

Restricted visitor policy

No conceivable spatial or temporal boundaries of the pandemic

Social isolation

Fear of losing family members, friends or colleagues

Frustration with political leaders

Frustration with administration for not having enough equipment/PPE or failure to protect/testing equipment

Uncertainty because of frequently changing information about COVID-19

Moral distress
Description

Care for COVID-19 patients is particularly strenuous, since wearing of protective gear is required and specific interventions, e.g. prone positioning, are physically demanding for HCWs

When hospitals become overburdened by the number of patients and at the same time suffer from absenteeism of diseased HCWs, the remaining staff may require to work serious amounts of extra hours

Close contact to infectious patients poses a risk for HCWs of getting infected and also a risk for transmission of SARS-CoV-2 to non-COVID-19 patients

Visiting restrictions for relatives and friends of patients causing regrets and sorrow for HCWs

No outlet to escape the situation because the pandemic as well as the stressors are not confined to the hospital, and not knowing when the pandemic is going to end

Family members of older age are at risk and cannot be seen, family celebrations cannot take place

HCWs may care for many severely ill patients, constantly aware of the danger of a COVID-19 infection

Perceived or real inconsistencies and management failures of political leaders increase the feelings of helplessness and being at the mercy of others

Perceived or real management failures of administrative staff when equipment for self-protection is not sufficiently available increase the feelings of being sacrificed, thus causing anger

HCWs are frequently asked about their opinion and for advice; they have to deal with a lot of uncertainty themselves and can be overwhelmed when facing individuals who do not understand social distancing and deny the danger of a pandemic spreading rapidly

Feelings of being left alone for rationing decisions on own moral standards when there are limited supporting structures and guidelines can lead to considerable moral distress

Moral imperatives, and, similarly, the legal and professional obligations derived from them, cannot be a unilateral commitment by HCWs; they should instead be considered as part of a societal contract consisting of mutual interests, rights and duties. HCWs should be able to rely on reciprocal obligations from others [8]. The scope of these reciprocal obligations is similarly context- and situation-dependent. In the setting of the COVID-19 pandemic, HCWs must be able to rely on a wide array of support, as well as the responsible behaviour of other members of society (table 2). For instance, situations in which HCWs put themselves at risk due to the lack of personal protective equipment must be strenuously avoided [9]. Similarly, reciprocal responsibility and solidarity also includes responsible behaviour of all members of society. Contact restrictions, social distancing and the wearing of facemasks in public can help save HCWs, health facilities and health systems from being overburdened. Finally, compensation for surviving dependents of HCWs who became infected during their work and died should be part of these reciprocal obligations as a matter of solidarity.

When demand for resources overwhelms supply, the inability to provide standard of care due to lack of staffing or equipment raises not only moral but also legal questions [10]. HCWs, and in particular physicians, may be at risk for being sued for not providing a normal standard of care despite being in a crisis for which they themselves could not reasonably be held responsible [11]. Working under a crisis standard of care that may, of necessity, be well below the ordinary standard of care, can be a source of extreme stress for all HCWs. This stress should not be compounded by the fear of legal prosecution, whether civil or criminal. The reciprocal responsibility of society at large should therefore entail the protection of HCWs in general from legal action based on a failure to provide an impossible-to-achieve standard of care in times when clinicians are forced to practice under crisis standards of care.

One additional remedy that has been proposed is to prioritise such individuals for vaccines and treatments that are limited in availability, with the rationale resting on the instrumental value of HCWs as well as on reciprocity or even reward for their commitment to society [12]. This argument has merit, particularly in the context of preserving the HCW workforce, when it comes to the distribution of a vaccine that will not be equally available for all from the outset. However, it will be challenging to balance this argument against prioritisation according to medical need. Preserving the lives of HCWs may help preserve one of 
TABLE 2 Reciprocal obligations for members of society with the goal of limiting the number of infected patients and reducing strain on the healthcare system

\begin{tabular}{|c|c|}
\hline Societal level & Responsibilities \\
\hline \multirow[t]{5}{*}{ All members of society } & Social distancing \\
\hline & Contact restrictions and avoidance of large group gatherings \\
\hline & Wearing of facemasks in public \\
\hline & Frequent handwashing \\
\hline & Protection of healthcare workers from unjustified legal action due to providing crisis standard of care \\
\hline \multirow{4}{*}{$\begin{array}{l}\text { Friends, family, colleagues and } \\
\text { neighbours }\end{array}$} & Active listening \\
\hline & Provide emotional support \\
\hline & Encourage healthcare workers to seek help from mental health specialists \\
\hline & Provide help for everyday duties (e.g. shopping, childcare) \\
\hline \multirow{6}{*}{$\begin{array}{l}\text { Healthcare administrators and } \\
\text { institutions }\end{array}$} & Ensure adequate personal protective equipment \\
\hline & $\begin{array}{l}\text { Limiting healthcare workers' workload by shifting tasks that are not absolutely necessary for patient } \\
\text { care to non-clinical personnel }\end{array}$ \\
\hline & Provide for counselling services \\
\hline & Develop “work-life balance" programmes \\
\hline & Promote self-care messaging \\
\hline & $\begin{array}{l}\text { Provide for education and teaching about recent scientific evidence related to the spread of SARS-CoV- } 2 \\
\text { and protective measures }\end{array}$ \\
\hline \multirow{5}{*}{$\begin{array}{l}\text { Unions and professional } \\
\text { organisations }\end{array}$} & Develop "work-life balance" programmes \\
\hline & Promote self-care messaging \\
\hline & $\begin{array}{l}\text { Develop educational programmes about recent scientific evidence related to the spread of SARS-CoV-2 } \\
\text { and protective measures }\end{array}$ \\
\hline & Advocate for healthcare workers' needs to employers, hospital administrations and governments \\
\hline & Protection of healthcare workers from unjustified legal action due to providing crisis standard of care \\
\hline \multirow{5}{*}{$\begin{array}{l}\text { Local, regional and national } \\
\text { government }\end{array}$} & Ensure adequate access to personal protective equipment for institutions \\
\hline & Support development of institutional and regional policies for rationing and triage \\
\hline & $\begin{array}{l}\text { Provide for financial protection of dependents of healthcare workers who become infected during } \\
\text { their work }\end{array}$ \\
\hline & Thorough explanation and public education regarding (scientific) rationale of restrictions and burdens \\
\hline & Protection of healthcare workers from unjustified legal action due to providing crisis standard of care \\
\hline
\end{tabular}

the scarcest resources in this pandemic and thereby potentially save more lives through their work at the bedside. However, prioritisation of HCWs will disproportionately benefit the educated and thereby aggravate existing social and racial disparities, which may be in conflict with egalitarian principles and equity. Several prioritisation guidelines for the distribution of COVID-19 vaccines have acknowledged prioritisation of frontline HCWs. However, other guidelines avoid taking a position with regard to favouring HCWs over elderly patients by awarding both groups the vaccine with equal priority [13, 14]. Both approaches have merit, but considering all arguments we advocate for prioritisation of frontline HCWs for SARS-CoV-2 vaccines.

Considering a broader range of treatments beyond vaccines, we believe prioritisation of HCWs for receipt of scarce resources should be subordinate to other more convincing principles. It is impossible to fairly judge instrumental value from the socially useful behaviour of a person, and to weigh it against other values. In addition, the judgement of instrumental value brings with it considerable danger of discrimination through overrating of an alleged instrumental value compared to morally competing principles, such as non-discrimination based on race, gender, age, disability or socioeconomic status.

The COVID-19 pandemic has put many health facilities and systems, and even entire societies, under unprecedented levels of stress. For reasons of justice and in order not to jeopardise the functioning of the health sector, HCWs must be able to rely on broad support to fulfil their duties for the benefit of society. Protecting and preserving the healthcare workforce has a direct bearing on the functioning of the entire healthcare system, which is paramount for the well-being of all societies.

\footnotetext{
Alexander Supady $\oplus^{1,2,3}$, J. Randall Curtis ${ }^{4,5}$, Crystal E. Brown $\oplus^{4,5,6}$, Daniel Duerschmied ${ }^{1,2}$, Lyn Anne von Zepelin ${ }^{1,2}$, Marc Moss ${ }^{7}$ and Daniel Brodie ${ }^{8,9}$

${ }^{1}$ Dept of Medicine III (Interdisciplinary Medical Intensive Care), Medical Center - University of Freiburg, Faculty of Medicine, University of Freiburg, Freiburg, Germany. ${ }^{2}$ Dept of Cardiology and Angiology I, Heart Center, University of Freiburg, Freiburg, Germany. ${ }^{3}$ Heidelberg Institute of Global Health, University of Heidelberg, Heidelberg, Germany. ${ }^{4}$ Cambia Palliative Care Center of Excellence at UW Medicine, Seattle, WA, USA. ${ }^{5}$ Division of Pulmonary, Critical Care, and Sleep Medicine, University of Washington, Seattle, WA, USA. ${ }^{6}$ Dept of Bioethics and Humanities, University of
} 
Washington, Seattle, WA, USA. ${ }^{7}$ Division of Pulmonary Sciences and Critical Care, University of Colorado School of Medicine, Aurora, CO, USA. ${ }^{8}$ Columbia University College of Physicians and Surgeons/New York-Presbyterian Hospital, New York, NY, USA. ${ }^{9}$ Center for Acute Respiratory Failure, Columbia University Medical Center, New York, NY, USA.

Correspondence: Alexander Supady, Medical Center - University of Freiburg, Dept of Medicine III (Interdisciplinary Medical Intensive Care), Hugstetter Strasse 55, 79106 Freiburg, Germany.

E-mail: alexander.supady@universitaets-herzzentrum.de

Received: 14 Jan 2021 | Accepted: 21 Jan 2021

Author contributions: A. Supady wrote the first draft of the manuscript following discussions with D. Brodie and J.R. Curtis. All co-authors revised the manuscript and added key content. All co-authors read and approved the final manuscript.

Conflict of interest: A. Supady reports grants and personal fees for lectures from CytoSorbents, personal fees for lectures from Abiomed, outside the submitted work. J.R. Curtis reports grants and personal fees from Cambia Health Foundation, grants from National Institutes of Health and National Palliative Care Research Center, outside the submitted work. C.E. Brown has nothing to disclose. D. Duerschmied has nothing to disclose. L.A. von Zepelin has nothing to disclose. M. Moss has nothing to disclose. D. Brodie reports grants from ALung Technologies, personal fees for advisory board work from Baxter, Xenios and Abiomed, and other (unpaid consultancy) from Hemovent, outside the submitted work.

\section{References}

1 Braquehais MD, Eiroa-Orosa FJ, Holmes KM, et al. Differences in physicians' and nurses' recent suicide attempts: an exploratory study. Arch Suicide Res 2016; 20: 273-279.

2 Azoulay E, Cariou A, Bruneel F, et al. Symptoms of anxiety, depression, and peritraumatic dissociation in critical care clinicians managing patients with COVID-19. A cross-sectional study. Am J Respir Crit Care Med 2020; 202: 1388-1398.

3 Butler CR, Wong SPY, Wightman AG, et al. US clinicians' experiences and perspectives on resource limitation and patient care during the COVID-19 pandemic. JAMA Netw Open 2020; 3: e2027315.

4 Nguyen LH, Drew DA, Graham MS, et al. Risk of COVID-19 among front-line health-care workers and the general community: a prospective cohort study. Lancet Public Health 2020; 5: e475-e483.

5 Costa DK, Moss M. The cost of caring: emotion, burnout, and psychological distress in critical care clinicians. Ann Am Thorac Soc 2018; 15: 787-790.

6 Jun J, Kelly Costa D. Supporting a precious resource: healthcare clinicians. Am J Respir Crit Care Med 2020; 202: $1330-1332$

7 Brody H, Avery EN. Medicine's duty to treat pandemic illness: solidarity and vulnerability. Hastings Cent Rep 2009; 39: 40-48.

8 World Health Organization. Ethical Considerations in Developing a Public Health Response to Pandemic Influenza. Geneva, WHO, 2007.

9 Nava S, Tonelli R, Clini EM. An Italian sacrifice to the COVID-19 epidemic. Eur Respir J 2020; 55: 2001445.

10 White DB, Lo B. Mitigating inequities and saving lives with ICU triage during the COVID-19 pandemic. Am J Respir Crit Care Med 2021; 203: 287-295.

11 Cohen IG, Crespo AM, White DB. Potential legal liability for withdrawing or withholding ventilators during COVID-19: assessing the risks and identifying needed reforms. JAMA 2020; 323: 1901-1902.

12 Persad G, Wertheimer A, Emanuel EJ. Principles for allocation of scarce medical interventions. Lancet 2009; 373: 423-431.

13 Dooling K, Marin M, Wallace M, et al. The Advisory Committee on Immunization Practices' updated interim recommendation for allocation of COVID-19 vaccine - United States, December 2020. MMWR Morb Mortal Wkly Rep 2021; 69: 1657-1660.

14 UK Government. Independent Report: Joint Committee on Vaccination and Immunisation: Advice on Priority Groups for COVID-19 Vaccination, 30 December 2020. London, Department of Health and Social Care, 2020. 